\title{
Importance of Relevant Visual Illustrations in Art Text Books
}

\author{
Nkami-Eval Nelson Elemi \\ Department of Visual Arts and Technology \\ Cross River University of Technology \\ Calabar, Cross River State, Nigeria \\ E-mail:nkamieval@gmail.com
}

Doi:10.5901/ajis.2013.v2n3p47

\begin{abstract}
A cursory survey of art textbooks used in tertiary educational institutions in Nigeria indicates that authors and publishers do not pay attention to the use of visual illustrations as a way of elucidating texts. While some art textbooks have badly printed visual illustrations, others do not have any illustrations at all, just as some have seemingly sufficient but irrelevant illustrations. These art textbooks appear to concentrate more on text rather than balancing textual information and visual illustrations for effective communication. Using the analysis of four randomly selected art textbooks used by visual arts students in Cross River University of Technology, Calabar, Nigeria, this paper seeks to verify the volume of text in art textbooks as compared to the number of relevant visual illustrations that go with them.
\end{abstract}

Keywords: Nigeria, Tertiary Education, Visual Illustration, Art Textbooks

\section{Introduction}

Many people have not placed importance on visual illustrations in texts, ignoring the fact that they are as relevant as textual communication/expressions. This is true of all text-based media like books, magazines, the Internet, etc. Whereas visual illustrations and textual matters are two separate means of communication, they nonetheless aim at similar objectives or end product, which is to pass on information to a targeted audience.

For the last 25 years, learning and understanding text has been investigated intensively, but research on examining the effectiveness of learning through visual images has received much less attention (Schnotz, 2002). However, a number of studies, especially in the 1970s, have emphasised the strength of our brain to store and recall images as opposed to text (Haber, 1970; Standing, 1973; Paivio, 1975). Even though textual expressions are communication in speech or writing, they sometimes confuse audiences by being verbose and not really transmitting the desired information. Therefore, textual communication possesses some level of disadvantage to the people or the person it is being said to. On the other hand, visual illustration is said to be a depiction such as a drawing, painting, photograph or an image that is created to elucidate or dictate visual information to its targeted audience (Illustration, 2013). Visual Illustrations are more self-explanatory, requiring much less textual communication to explain issues. Even the simple minded can pick meanings from visual illustrations. Unlike textual communication, visual illustrations can attract attention, aid retention, enhance understanding or create contexts because it is far easier to 'read' pictures than words. It is widely known that experience is the best teacher. Therefore visual illustrations could be said to be 'experience', because, even though an event didn't occur in the life of the audience, it actually appears to them as a previous experience of the person or thing in the illustration, which seems as though they participated. In an attempt to look in both directions, we may discover that texts are not as explicit as they are made to seem. Yet relevant visual illustrations are as always, clearer and more direct. No matter how little they are represented, they pass on direct and instant information to the audience, whereas textual form of communication does not possess any of these qualities, and only fewer people can grasp it, thereby defeating the purpose of communication.

The current situation of art textbooks used by visual arts students in Cross River University of Technology is such that some visual illustrations in these art textbooks are badly printed, while some are scanty and some have sufficient illustrations that seem not to be relevant. These arts textbooks appear to concentrate more on text rather than balancing textual information and visual illustrations for effective communication. Using the analysis of four randomly selected art textbooks used by visual arts students in CRUTECH, this paper seeks to verify the volume of text in art textbooks as compared to the number of relevant visual illustrations that go with them. 


\section{Area of Study}

This study uses art text books in Tertiary institutions using Cross River University of Technology (CRUTECH), Calabar, Cross River State, Nigeria as a case study. There are several tertiary institutions in Nigeria, some of which offer art as a course of study. Most of these art students find their way into art not by choice but out of the frustration of constantly writing Joint Admissions Matriculation Examinations, while some are pushed in by the institution because the quota for their initial course of choice had been exceeded. So the Department of art is used as a dumping ground for these students who originally had little or no interest in the arts whatsoever. Four art text books used by visual arts students in CRUTECH are analysed, to derive data on visual illustrations embedded in the textual writings, in order to make the most meaningful communications to the students. This study delimits itself to only four art text books used by visual arts students in CRUTECH, some of which contain clear line drawings, photographs, prints and computer designed illustrations, while some contain strictly textual forms of communication. In scope, the study is also delimited to CRUTECH because it is the only tertiary institution in Calabar that offers fine arts as a course of study.

\section{Statement of the Problem}

Many recommended tertiary art text books in Nigeria do not include relevant visual illustrations, whereas most of these art books contain textual forms of communication from lines A-Z. It is not enough to take pictures of works of art, drawings or make illustrations of them. Certain principles must be considered and followed. In one of his classes Professor Chike Aniakor (2013) clearly stated that it is not enough to take pictures or make drawings of works of art. Details of these works must be considered in order to reveal texture, medium, symbols and forms that could be relevant to a student or researcher, which helps in paper analysis and work description. Most tertiary art text books used in CRUTECH, either have no illustrations at all or have several but irrelevant pictures/illustrations that are of little or no use to its targeted audience.

\section{Visual Literacy and Textual Communication}

Wileman (1993) defines visual literacy as "the ability to 'read,' interpret, and understand information presented in pictorial or graphic images" (p144). Associated with visual literacy is visual thinking, described as "the ability to turn information of all types into pictures, graphics or forms that help communicate the information" (Wileman, p. 144). This simply means that pictures are more explicit than words. Textual communication is descriptive, that is, giving account of something by giving details of its characteristics. These details may not be fully understood because of the verboseness of the text. Zuboff (1988) describes such characteristics as "the textualization of sociality" in which information and social exchange become overly textualised. However, Sproull and Kiesler (1986) have said that in textual communication, most of the "social context cues" are eliminated. Text only tries to describe or represent, leaving the imagination of it's audience running wild. But visual illustrations describe in a more practical and realistic way, giving the minds of it's audience a focus and better understanding. According to Keegan (2007), illustrations have been part of our learning mechanism since our childhood, as images are used in storybooks to stimulate our imaginations. So, for students who are learning new subject areas or topics unfamiliar to them, it is like being a child again, reinforcing the need for images and illustrations to help students visualise and relate to them. Relevant visual illustrations should be made to go with textual communication. Most people see illustrations as a child's thing and should not be applicable to adults, forgetting that no two humans develop the same way. Good illustrations can contribute to the overall development of both child and adult by triggering his/her imagination, arousing perception and developing potentials.

\section{Methodology}

Four art textbooks used by art students in Cross River University of Technology were randomly selected for this study. The textbooks are Art Teaching in African Schools (Talabi 1979), Research Methods in Visual Arts (Egonwa 2012), Issues in Modern Art in Nigeria (Ikpakronyi 2011) and Nigerian Arts: Introductory Notes (Egonwa 2011). Each textbook was carefully analysed along with all the visual illustrations. Selected illustrations were scanned and used for the research. The illustrations in each of the books were counted and classified under: relevant, not relevant, clear and not clear. The sections in which the visual illustrations are placed were carefully read and compared with the illustrations to determine whether they were relevant or not. The illustrations were also scrutinized in terms of how well they have been 
produced in the book to enable students to actually gain information from them. All the visual data were tabulated accordingly (see Table 1).

Table 1: Analyses of Illustrations in Four Arts textbooks

\begin{tabular}{|c|c|c|c|c|c|c|c|}
\hline S/N & Author & Title & $\begin{array}{c}\text { Number of } \\
\text { Visual } \\
\text { Illustrations }\end{array}$ & $\begin{array}{c}\text { Number of } \\
\text { Relevant } \\
\text { Illustrations }\end{array}$ & $\begin{array}{c}\text { Number of } \\
\text { Irrelevant } \\
\text { Illustrations }\end{array}$ & $\begin{array}{c}\text { Number of Clear } \\
\text { Illustrations }\end{array}$ & $\begin{array}{c}\text { Number of NOT } \\
\text { clear Illustrations }\end{array}$ \\
\hline 1 & $\begin{array}{c}\text { Talabi, } \\
\text { George }\end{array}$ & $\begin{array}{c}\text { Art Teaching in African } \\
\text { Schools(1979) }\end{array}$ & 140 & $\begin{array}{c}123 \\
(87.9 \%)\end{array}$ & $\begin{array}{c}17 \\
(12.1 \%)\end{array}$ & $\begin{array}{c}105 \\
(75 \%)\end{array}$ & $\begin{array}{c}35 \\
(25 \%)\end{array}$ \\
\hline 2 & $\begin{array}{c}\text { Egonwa, } \\
\text { Osa }\end{array}$ & $\begin{array}{c}\text { Research Methods in } \\
\text { Visual Arts (2012) }\end{array}$ & 10 & $\begin{array}{c}8 \\
(80 \%)\end{array}$ & $\begin{array}{c}2 \\
(20 \%)\end{array}$ & $(60 \%)$ & $(40 \%)$ \\
\hline 3 & $\begin{array}{c}\text { Ikpakronyi, } \\
\text { Simon }\end{array}$ & $\begin{array}{c}\text { Issues in Modern Art in } \\
\text { Nigeria (2011) }\end{array}$ & 0 & 0 & 0 & 0 & 0 \\
\hline 4 & $\begin{array}{c}\text { Egonwa, } \\
\text { Osa }\end{array}$ & $\begin{array}{c}\text { Nigerian Arts: Introductory } \\
\text { Notes (2011) }\end{array}$ & 139 & 80 & 59 & 59 & 80 \\
$(57.6 \%)$ & $(42.4 \%)$ & $(42.4 \%)$ & $(57.6 \%)$ \\
\hline
\end{tabular}

\section{Result}

The result of the analysis shows that: Art Teaching in African Schools (Talabi 1979) has a total of 140 illustrations. Of this number, 123 (or 87.9\%) were relevant, 17 (or 12.1\%) were irrelevant whereas 105 (or 75\%) were clear and 35 (or 25\%) were not clear. Research Methods in Visual Arts (Egonwa 2012) has a total of 10 illustrations. Of this number, 8 (or 80\%) were relevant, 2 (or 20\%) were irrelevant whereas 6 (or 60\%) were clear and 4 (40\%) were not clear. However: Issues in Modern Art in Nigeria (Ikpakronyi 2011) has no visual illustrations whatsoever (see table1). Finally, Nigerian Arts: Introductory Notes (Egonwa 2011) has a total of 139 visual illustrations. Of this number, 80 (or 57.6\%) were relevant, 59 (or 42.4\%) were irrelevant, whereas 59 (or 42.4\%) were clear and 80 (57.6\%) were not clear.

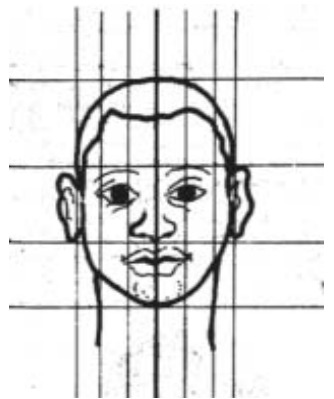

Figure 1: Relevant illustration of a human face (Talabi 1979, p.47.)

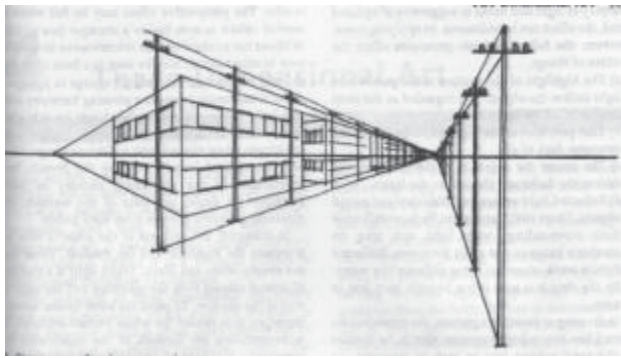

Figure 2: Relevant illustration of a perspective drawing (Talabi 1979, p.55.) 


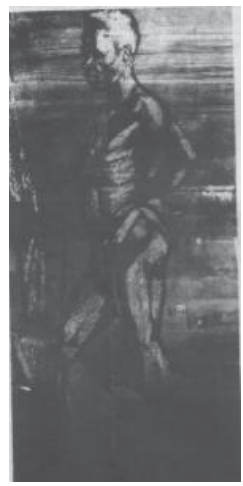

Figure 3: An example of an irrelevant illustration in Talabi (1979, p.44.)

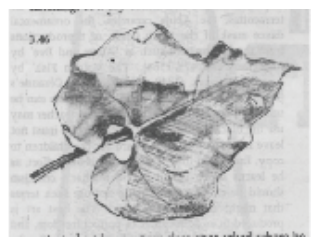

Figure 4: An example of a clear illustration in Talabi $(1979$, p.47.)

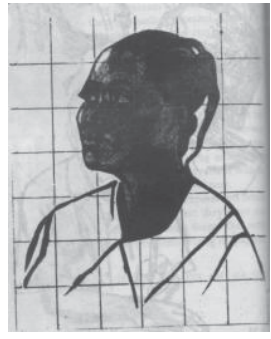

Figure 5: An example of an unclear illustration in Talabi $(1979$, p.50.). One can see that the woman's face is not clear and students cannot gain much from the illustration

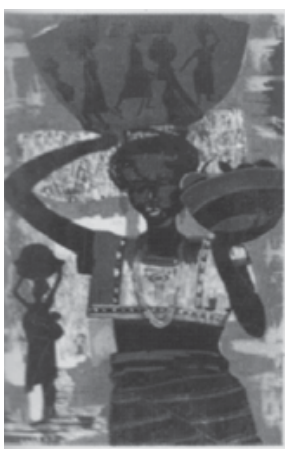

Figure 6: A relevant illustration of a painting (Egonwa 2012, p.85.) 


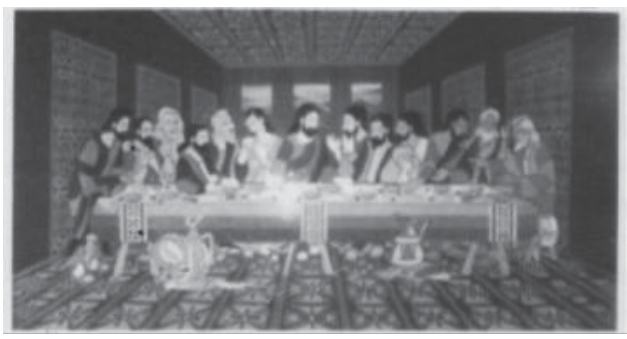

Figure 7: An example of an illustration that is not clear. The faces and other important details are not visible (Egonwa 2012, p.82.)

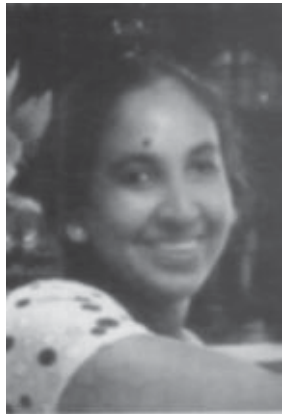

Figure 7: An example of a clear illustration that is not relevant in the text because the space could have served a better function if it were used to show an art work for discussion. The artist's image is not as relevant as that of the works (Egonwa 2012, p.81.)

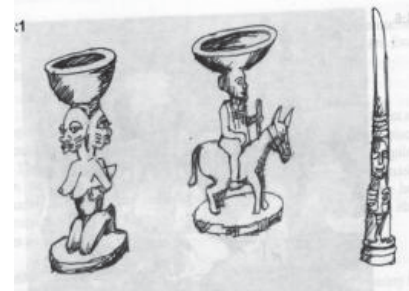

Figure 8: A relevant illustration of ivory clappers (Egonwa 2011, p.52.)

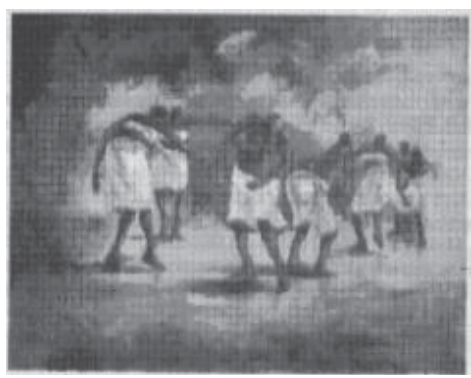

Figure 9: An irrelevant illustration of a painting (Egonwa 2011, p.149.) 


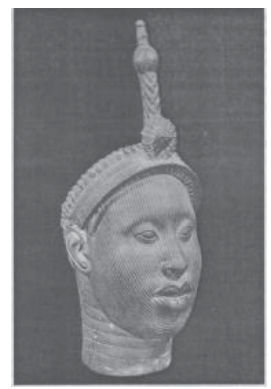

Figure 10: An example of a very clear illustration of an Ife bronze head (Egonwa 2011, p.25.)

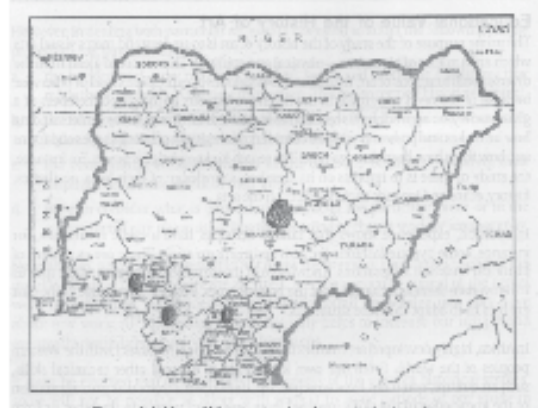

Figure 11: An example of a very unclear illustration of the map of Nigeria (Egonwa 2011, p.14.)

\section{Discussion}

Figures 7, 4 and 10 are examples of clear illustrations because the true forms and textures are clearly represented. For example, any art student who reads about the Ife Bronzes in Figure 10 can find it easy to understand and analyse because of its clarity in texture and details that seem to be real. With this effective communication has been established. Even though Figure 7 is cited here as a clear illustration, it is not actually a relevant illustration because the picture of the artist was not relevant on that space. It sends out no useful information whatsoever to the student. It would have been better to put up an actual painting by the artist that should have been discussed and analyzed for the student to understand.

Figures 3,5 and 11 are examples of illustrations that are not clear because their true forms and textures are not clearly represented. For example, any art student who reads about the drawing of a human form in Plate 5 would have it difficult seeing the image, understanding it and analysing its form. Because they can't see clearly, the students will misinterpret and make wrong assumptions which leads to ineffective communication. Just as Aniakor (2013) had said, pictures that are not clear would not give true information.

Unlike Figures 3, 7 and 9 that are irrelevant in the places where they are put in the textbooks, Figures 2, 6 and 8 are relevant because they relate to the information in the text and they explain the information that is communicated in the text. For example, Figure 2 is very relevant because it relates directly to perspective and it enables the students to see and understand the techniques. And for this reason, effective communication has taken place because relevant visual illustrations have been used to communicate relevant ideas to students in the textbooks.

\section{Conclusion}

From the analysis above, it is clear that some art textbooks used by art students in Cross River University of Technology (Nigeria) sometimes have unclear visual illustrations that may also be irrelevant. Other illustrations may be clear and still be irrelevant, while some visual art textbooks do not have visual illustrations at all. Another problem that arises is that some art textbooks have unclear illustrations that are relevant. Whichever way, all of these problems are negative to 
teaching and learning processes in the Nigerian universities because unclear or irrelevant illustrations lead to ineffective communication (Aniakor 2013 and Keegan 2007). Aniakor (2013) and Keegan (2007:58) note that images "assist students make visual associations and, more importantly, remain focused in lectures". In conclusion it is important that visual art textbooks use visual illustrations that are relevant to the subject matter and are also clear and easy to understand by art students. The results presented here are tentative, since a much deeper approach and much broader methodology needs to be formulated in which many more art textbooks are used and art student can be respondents in a controlled experiment.

\section{References}

Aniakor, C. (2013). Postgraduate lecture. Department of Visual Arts \&Technology, Cross River University of Technology, Calabar.

Egonwa, O. (2011). Nigerian arts: Introductory notes. Ibadan: Ababa Press.

Egonwa, O. (2012). Research methods in visual arts. Ibadan: Ababa Press.

Haber, R. N. (1970). How we remember what we see. Scientific American. 222 (May): 104-112. [APX III ].

Ikpakronyi, S. (2011). "Modern Nigerian art: its development and characteristics." Modern Nigerian art: Art Expo Las Vegas 2008. Pages $1-17$

Illustration (2013). Wikipedia <http://en.wikipedia.org/wiki/llustration> Date accessed 31/01/2013

Paivio, A. (1975) "Imagery and long-term memory". In A. Kennedy and A. Wilkes (eds.) Long Term Memory. London: John Wiley and Sons.

Paivio, A. (1986) Mental representations: A dual coding approach. Oxford: Oxford University Press.

Schnotz, W. (2002) "Towards an integrated view of learning from text and visual displays", Educational Psychology Review, 14 (1), 101120.

Sproull, L., \& Kiesler, S. (1991). Connections: new ways of working in the networked organization. Cambridge: The MIT Press.

Standing, L. (1973). "Learning 10000 pictures". Quarterly Journal of Experimental Psychology, 25(2), 207-222.

Talabi, G. (1979). Art teaching in African schools. Ibadan: Heinemann.

Wileman, R. E. (1993). Visual communicating. Englewood Cliffs, N.J.: Educational Technology Publications.

Zuboff, S. (1988). In the age of the smart machine: the future of work and power. New York, NY: Basic Books. 
